\title{
An Experimental Study on using of Waste Marble Water as Partial Replacement of Portable Water in Concrete
}

\author{
Pratik V. Shah ${ }^{(1)}$, Rushit Vaghasiya, Saumil Savaliya, Vishal Nolkha ${ }^{(2)}$ \\ (1) Asst. Professor, Dept. of Civil Engineering, R.N.G.P.I.T. College, Gujarat, India \\ (2) Students, Dept. of Civil Engineering, R.N.G.P.I.T. College, Gujarat, India.
}

\begin{abstract}
Portable Water is the main ingredient in making of concrete. Without PW making of concrete is not possible. As there are crisis of water in the world. We need to find out the second alternative of $\mathrm{PW}$ for making in concrete. In these research we have study about the use of waste marble water in making of concrete. The concrete was mixed design for $M-25$ grade of concrete with moderate exposure condition. The PW was replaced with WMW at an interval of $25 \%$, that is $0 \%$, $25 \%, 50 \%, 75 \% \& 100 \%$. The cube and cylinder were casted of standard sizes and they were tested at 7 days \& 28 days after curing. The result shows that as we replace the PW with WMW by and interval the strength increases but when we replace the PW with WMW by $50 \%$ we get the maximum Compressive and tensile strength. The \% increase in the strength at $50 \%$ replacement is.
\end{abstract}

Key Words: Waste Marble Water, Portable water, compressive strength, tensile strength, $M-25$ grade of concrete.
Abbreviations:
$\mathrm{CA}=$ Coarse Aggregate
CTM = Compression Testing Machine
FA $\quad$ Fine Aggregate
PW $\quad=$ Portable Water
WMW = Waste Marble Water

\subsection{INTRODUCTION}

As India is an undeveloped country for developing itself it requires a good infrastructure and for that concrete is in high demand. And for the production of concrete cement \& water are main ingredients other than sand \& coarse aggregate. Approximately around 150 liter of water is required per $\mathrm{m}^{3}$ production of concrete. And as we all know only $3 \%$ water is available for drinking and out of that also only $1 \%$ is available as ground source. Generally in construction the water is directly bored from the ground or taken from the government bodies. Because of this reason there is a decrease in the ground water level in India. Due to which there is scarcity of portable water, and many construction work have been stopped. We need to find the other alternative of $\mathrm{PW}$ as these resources are getting reduce day by day.

The other researchers have study about using the primary treated waste water, secondary treated waste water, but no one has study about the effect of waste marble water on concrete. As in marble industry water is a main source for cutting the marble in to desired shape. The waste water is directly drained.
This study aims on using the WMW as a partial replacement of PW in making of concrete. And the partial replacement are done at an interval of $25 \%$, that is PW will be replaced by $0 \%, 25 \%, 50 \%, 100 \%$ of WMW.

\subsection{LITERATURE REVIEW:}

E.W. Gadzama, ${ }^{(\mathbf{1})}$ "Effects of Sugar Factory Wastewater as Mixing Water on the Properties of Normal Strength Concrete". The concrete mix of $25 \mathrm{MPa}$ with proportion $1: 2$ : 4 with w/c ratio of 0.56 . The PW was replaced with sugar waste water in $0 \%, 75 \%, 100 \%$. In the paper they have replace the PW as total or partial replacement of mixing water in concrete as well as for curing it. After reading we can conclude that target strength as 28 days was ranged between $83 \%$ to $91 \%$ but if we extend the curing duration to 90 days the concrete cubes produce more strength than targeted strength.

\subsection{METHODOLOGY}

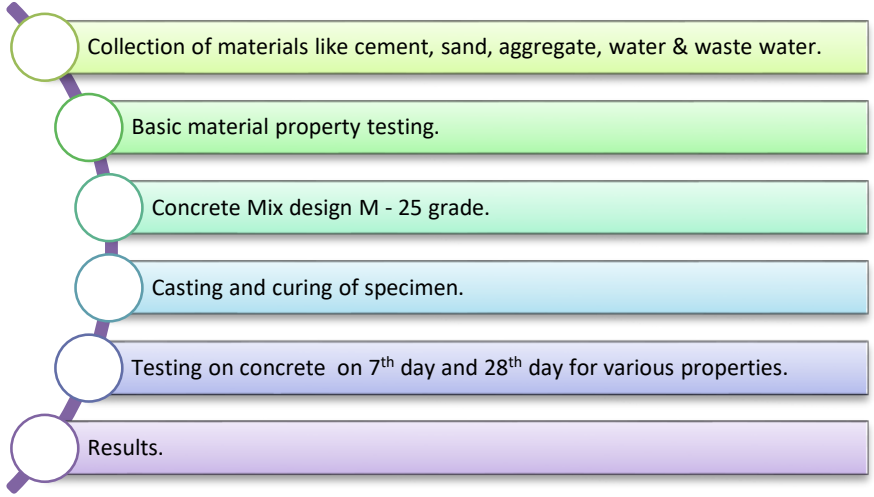

Figure 1: Flow chart of Methodology

\subsection{EXPERIMENTAL WORK}

Cement: it is used for binding the concrete. We have used PPC of 53 grade.

Coarse Aggregate: Coarse aggregate passing through sieve of size $20 \mathrm{~mm}$ and retained on $12.5 \mathrm{~mm}$ were used. The specific gravity was 2.83 and water absorption was $2.47 \%$

Fine Aggregate: Fine aggregate was found to be from zone III. The specific gravity was 2.68 and water absorption was $2.21 \%$.

Portable Water: PW was collected directly from the tap which was used for drinking purpose. The table - 1 shows the chemical property of PW used in construction. 
Waste Marble Water: WMW samples were collected from marble cutting and polished factory in Bardoli region. The table - 1 shows the chemical property of WMW with the permissible of IS : 456 -2000.

Table -1 : Chemical Properties of Waters

\begin{tabular}{|c|c|c|c|}
\hline TEST & PW & WMW & $\begin{array}{c}\text { Permissible } \\
\text { Limit As Per IS } \\
\mathbf{4 5 6 - 2 0 0 0}\end{array}$ \\
\hline -pH & 6.6 & 8.6 & $>6$ \\
\hline $\begin{array}{c}\text { CHLORIDE } \\
\text { (mg/l) }\end{array}$ & 100 & 119 & 2000 \\
\hline $\begin{array}{c}\text { SHULPHATE } \\
\text { (mg/l) }\end{array}$ & 250 & 70.34 & 400 \\
\hline $\begin{array}{c}\text { SUSPENDE } \\
\text { MATTER } \\
\text { (mg/l) }\end{array}$ & 10 & 932 & 2000 \\
\hline $\begin{array}{c}\text { SUSPENDE } \\
\text { MATTER } \\
\text { (mg/l) }\end{array}$ & 10 & 932 & 2000 \\
\hline
\end{tabular}

Mix Design of concrete: The nominal mix design of concrete was done according to the IS : 10262 - 2019, and concrete specimen was designed for a grade M25. Table - 2 shows the mix proportion of concrete. There is partial replacement of PW with the WMW.

Table - 2: Mix Proportions of Concrete

\begin{tabular}{|c|c|c|c|c|c|}
\hline $\begin{array}{c}\text { Mix } \\
(\mathbf{\%})\end{array}$ & $\begin{array}{c}\text { Cement } \\
\left(\mathbf{k g} / \mathbf{m}^{\mathbf{3}}\right)\end{array}$ & $\begin{array}{c}\mathbf{W M W} \\
\left(\mathbf{k g} / \mathbf{m}^{\mathbf{3}}\right)\end{array}$ & $\begin{array}{c}\mathbf{P W} \\
\left(\mathbf{k g} / \mathbf{m}^{\mathbf{3}}\right)\end{array}$ & $\begin{array}{c}\mathbf{F A} \\
\left(\mathbf{k g} / \mathbf{m}^{\mathbf{3}}\right)\end{array}$ & $\begin{array}{c}\mathbf{C A} \\
\left(\mathbf{k g} / \mathbf{m}^{3}\right)\end{array}$ \\
\hline $\mathbf{0}$ & 438 & 0 & 197 & 580 & 1156 \\
\hline $\mathbf{2 5}$ & 438 & 49 & 148 & 580 & 1156 \\
\hline $\mathbf{5 0}$ & 438 & 99 & 99 & 580 & 1156 \\
\hline $\mathbf{7 5}$ & 438 & 148 & 49 & 580 & 1156 \\
\hline $\mathbf{1 0 0}$ & 438 & 197 & 0 & 580 & 1156 \\
\hline
\end{tabular}

Preparation of Specimen: Cubes and cylinder were casted as per above mentioned concrete mix. Totally 40 cubes and 30 cylinders were casted for these project work. Following table indicates number of cubes and cylinder were casted.

Table -3 : No. of Cube \& Cylinder for curing

\begin{tabular}{|c|c|c|c|c|}
\hline \multirow{2}{*}{$\begin{array}{c}\text { PARTIAL } \\
\text { REPACEMENT OF }\end{array}$} & \multicolumn{3}{|c|}{ CURING PERIOD (DAYS) } \\
\cline { 2 - 5 } PW & $\mathbf{7}$ & $\mathbf{2 8}$ & $\mathbf{7}$ & $\mathbf{2 8}$ \\
\hline $\mathbf{0 \%}$ & 4 & 4 & 3 & 3 \\
\hline $\mathbf{2 5} \%$ WMW & 4 & 4 & 3 & 3 \\
\hline $\mathbf{5 0} \%$ WMW & 4 & 4 & 3 & 3 \\
\hline $\mathbf{7 5} \%$ WMW & 4 & 4 & 3 & 3 \\
\hline 100 \% WMW & 4 & 4 & 3 & 3 \\
\hline
\end{tabular}

Curing: IS : 516 guidelines were followed for the compacting and curing of concrete specimen.

\subsection{TESTS \& RESULTS}

Compressive Strength Test: IS : 516 was followed for the test. CTM used for testing was servo controlled and $3000 \mathrm{kN}$ capacity. The casted cube were of standard size of $150 \mathrm{~mm} *$ $150 \mathrm{~mm} * 150 \mathrm{~mm}$. Result are shown in fig. 2 for 7 days and fig. 3 for 28 days.

Split Tensile Test: IS : 516 was followed for the test. CTM used for testing was servo controlled and $3000 \mathrm{kN}$ capacity. The casted cylinder were of standard size of $150 \mathrm{~mm}$ dia. $300 \mathrm{~mm}$ height. Result are shown in fig. 4 for 7 days and fig. 5 for 28 days.
Slump Cone Test: IS : 1199 was followed for the test. A cone is used for determining the workability of concrete. Results are displayed in table.

Ultra Pulse Velocity Test: IS : 13311 (Part - 1) was followed for the test. These test was done to find the quality of concrete. After performing the test we have found out that the quality of concrete has come good and UPV was ranging from 3.77 to $4.18 \mathrm{~km} / \mathrm{sec}$.

Table - 4: Slump Value

\begin{tabular}{|c|c|}
\hline Design Mix & Slump Value \\
\hline $\mathbf{0 \%}$ & 100 \\
\hline $\mathbf{2 5 \%}$ WMW & 100 \\
\hline $\mathbf{5 0 \%}$ WMW & 100 \\
\hline $\mathbf{1 0 0 \%}$ WMW & 95 \\
\hline
\end{tabular}

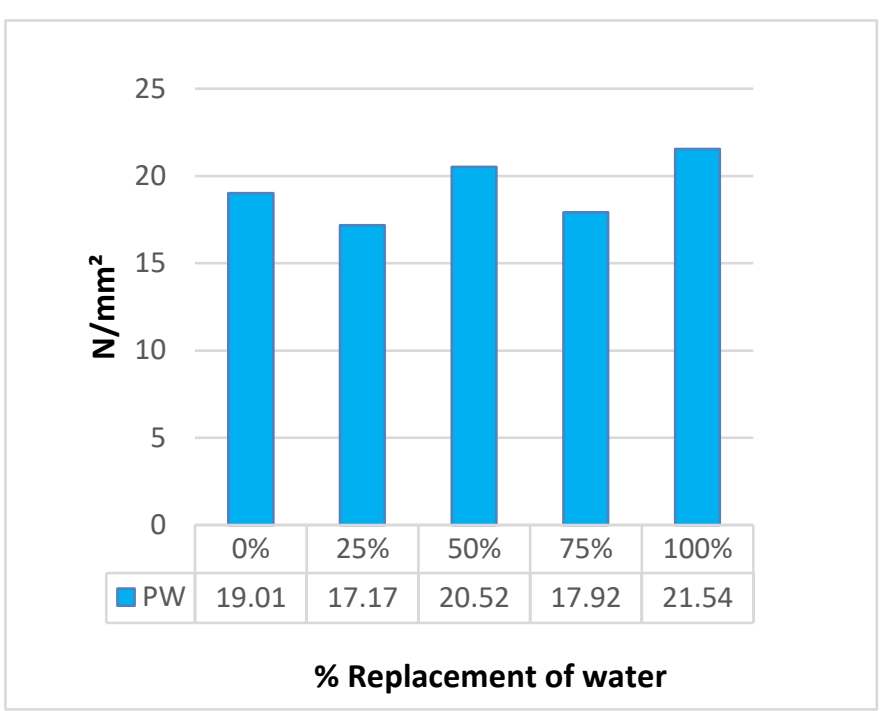

Figure 2: Compressive strength of Cube (7 Days)

\subsection{DICUSSIONS \& CONCLUSIONS:}

From the test performed, we can clearly say that WMW can be used in the construction work. As the chemical analysis was with in the permissible limit as per IS : $456-2000$. And it can also be used for curing purpose. The partial replacement of PW shows increase in compressive strength as well as the split tensile strength.

When we are replacing the PW by $25 \%, 75 \%$ and $100 \%$ there is reduction in the split tensile strength ranging from $14.96 \%, 6.20 \%$ and $6.93 \%$ respectively. $100 \%$ replacement is possible as there is negligible reduction in the tensile strength of concrete.

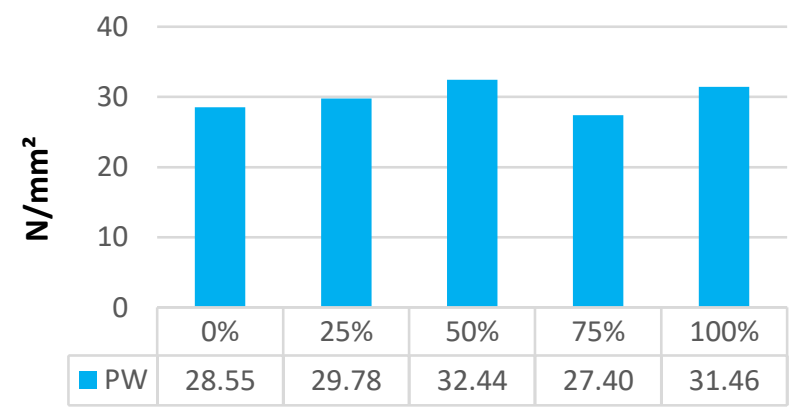

\section{\% Replacement of water}

Figure 3: Compressive strength of Cube (28 Days) 


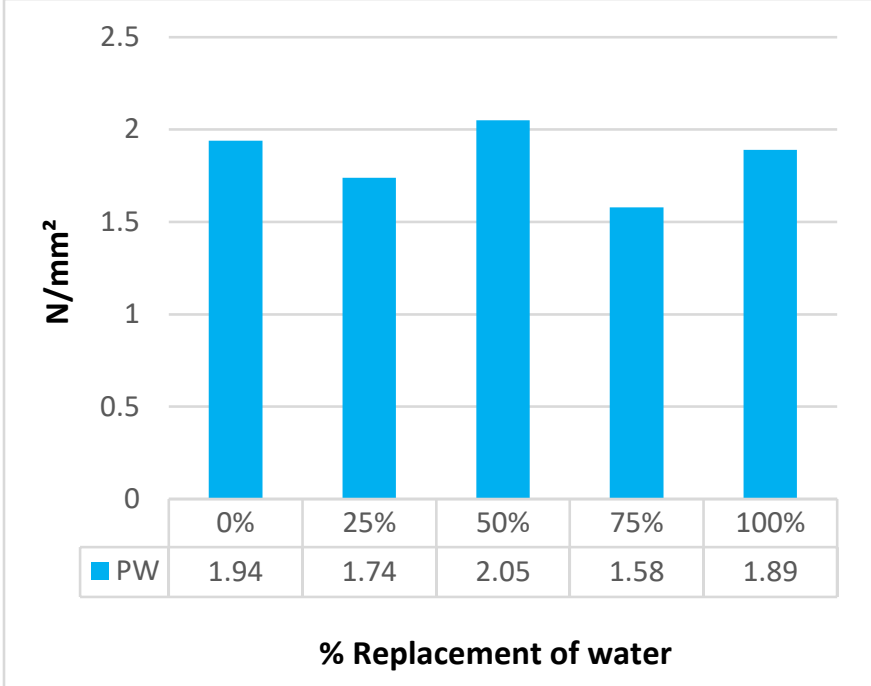

Figure 4: Split tensile strength of cylinder (7 Days)

- The consistency, initial and final setting time was found to be within the permissible limit as per IS code.

- When PW is replaced by $50 \%$ of WMW, there is increase in the compressive strength by $13.63 \%$ and in tensile strength by $8.03 \%$.

- When the PW is replaced by $100 \%$ of WMW, there is increase in the compressive strength by $10.19 \%$ but there is decrease in the tensile strength by $6.93 \%$.

- We can use the WMW as a partial replacement of PW.

- Workability of concrete was good.

- The quality of concrete with partial replacement of PW was also found good.

- Concrete cost can be reduced by using the WMW in construction.

- The amount of water saved when we are replacing $\mathrm{PW}$ with $50 \%$ and $100 \%$ per $\mathrm{m}^{3}$ production of M25 grade of concrete 99 and 197 liters.

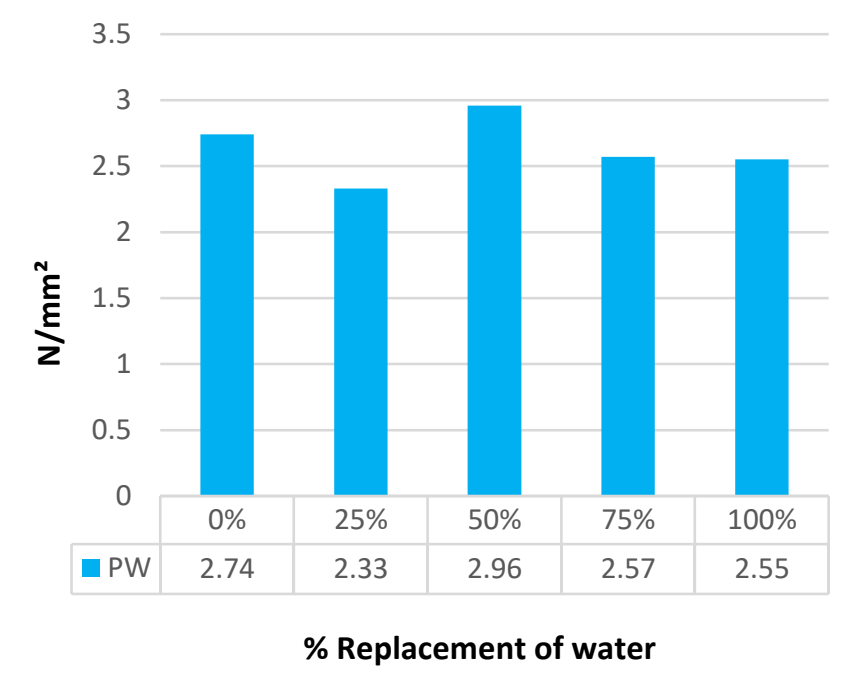

Figure 5: Split tensile strength of cylinder (28 Days)

\section{REFERENCES}

[1] E.W. Gadzama, O. J. Ekele, V. E. Anametemfiok and A. U. Abubakar (2015), "Effects of Sugar Factory Wastewater as Mixing Water on the Properties of Normal Strength Concrete"

[2] IS: 10262-2009 (RA-2019), "Concrete Mix Proportioning Guidelines"

[3] IS: 2386(PART-1,3,4) 1963 (RA-2016), "Methods of Test for Aggregates for Concrete"

[4] IS: 4031-1988 (RA-2014), "Methods of Physical Tests for Hydraulic Cement"

[5] IS: 456-2000 (RA-2016), "Plain And Reinforced Concrete Code of Practice"

[6] IS: 516-1959, "Methods of 'Tests For Strength of Concrete" 